\title{
Pseudo-Aneurysm of Lingual Artery a Rare Complication of Squamous Cell Carcinoma of Tongue and a Cause of Oral Bleed
}

Imtiaz Ali*, Hina Naseer, Raisa Altaf, Muhammad Ayub Mansoor, Danial Khalid

Department of Radiology, Liaquat National Hospital and Medical College, Karachi, Pakistan

Correspondence to: Imtiaz Ali, Department of Radiology, Liaquat National Hospital and Medical College, Karachi, Pakistan.

Received date: February 08, 2022; Accepted date: February 21, 2022; Published date: February 28, 2022

Citation: Ali I, Naseer H, Altaf R, et al. (2022) Pseudo-Aneurysm of Lingual Artery a Rare Complication of Squamous Cell Carcinoma of Tongue and a Cause of Oral Bleed. J Med Res Surg 3(1): pp. 13-14. doi: 10.52916/jmrs224069

Copyright: (C2022 Ali l, et al. This is an open-access article distributed under the terms of the Creative Commons Attribution License, which permits unrestricted use, distribution and reproduction in any medium, provided the original author and source are credited.

\section{ABSTRACT}

Pseudo-aneurysm of lingual artery a branch of external carotid artery is rarely seen. Most of cases of pseudo-aneurysm occur after trauma, surgery, inflammation, post chemotherapy, radiotherapy and infection. Pseudo-aneurysm of lingual artery secondary to lingual carcinoma with oral bleeding is a rare presentation, hence we discuss the $\mathrm{CT}$ imaging findings of lingual artery pseudo-aneurysm in a patient with known case of carcinoma of tongue on chemotherapy and radiotherapy presented with oral bleeding.

\section{Keywords:}

Pseudo-aneurysm, Lingual artery, CT scan, Lingual carcinoma

\section{Introduction}

Pseudo-aneurysms of lingual are very rare can be develop secondary to iatrogenic injury during surgery, blunt penetrating trauma, inflammation, post chemo-radiotherapy, or radiotherapy. They may cause the life threatening bleeding if not recognized and treated early [1-3]. Most of these are identified as the result of massive oral bleed. These require urgent hemostasis like clipping, ligation, embolization or ultrasound guided percutaneous thrombin [2]. Pseudo-aneurysm are those who lack the three layers of vessels wall which results from arterial damage [4]. They are differ from true aneurysm and composed of connective fibrous tissue results from leaking of blood through the damage wall into the adjacent fibrous connective tissue resulting in formation of blood clot that subsequently liquefies. Further bleeding can occur causing expansion of pseudo-aneurysm [5]. All histopathological analyzed aneurysm of lingual artery have been described as pseudo-anerurysm [3].

\section{Case Report}

A 42 years old male known case of hypertension, diabetes and histopathological diagnosed case of squamous cell carcinoma of tongue with metastasis on chemo-radiotherapy presented to the emergency department of our hospital with complaints of bleeding from mouth, difficulty to open the mouth and buccal pain. On examination, he was tachypneic, pale and had large ulcerated fungating mass within the mouth involving the tongue. His laboratory investigations showed hemoglobin of 4 $\mathrm{g} / \mathrm{dl}$. Other baseline investigation were within the normal range. He underwent through the Computed Tomography (CT) scan neck with contrast to rule the cause of oral bleed, which demonstrate a large lobulated heterogeneously enhancing mass involving intrinsic muscles of tongue extending into floor of the mouth consistent with biopsy proven squamous cell carcinoma. A small area of contrast filled lobulated out pouching seen within the mass on right side of tongue communicating with the right lingual artery representing pseudo-aneurysm (Figure 1 and 2).

Patient was referred to intervention radiology department for angio-embolization. Unfortunately the patient denied for both surgical ligation, excision and angio-embolization and lost to follow after medical symptomatic management and blood transfusion from our hospital due to financial constraints and went to the another welfare based tertiary care hospital for angio-embolization/surgical treatment and further management.

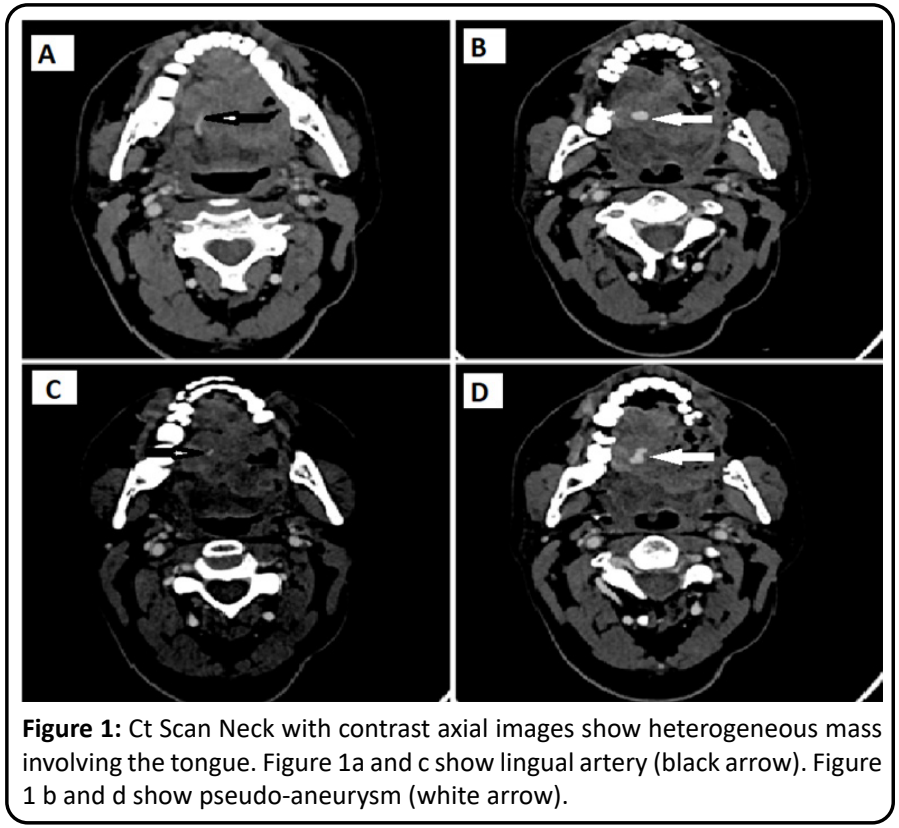

\section{Discussion}

Carotid artery aneurysms are very rarely seen in clinical practice [4]. External carotid artery aneurysms comprises of $2.2 \%$ of all cervical carotid artery aneurysms from which superficial temporal and facial arteries are the most commonly develops pseudo-aneurysm [3,4]. They are very rare as compared to other peripheral arteries [6]. True aneurysms are develop secondary to either congenital or acquired weakness in all three layers 


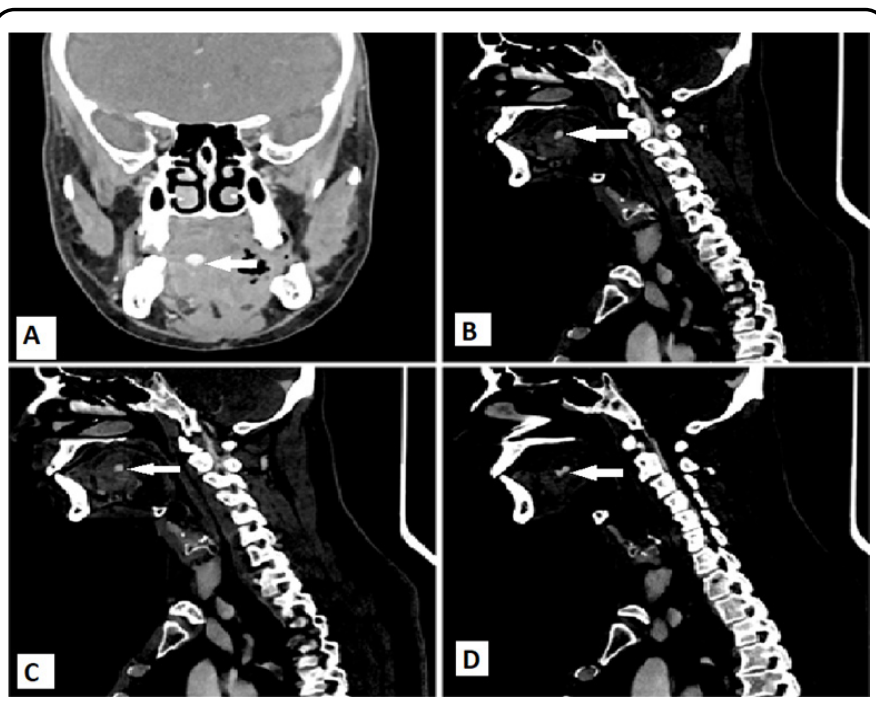

Figure 2: CT scan neck with contrast sagittal and coronal images show heterogeneous mass involving the tongue. The white arrows show pseudaneurysm arising from the lingual artery.

of vessel wall. While false aneurysm are develop secondary to localized laceration in arterial wall caused trauma, infection, surgery or radiofrequency [2]. Lingual pseudo-aneurysm are considerably very rare $[1,3,4,7]$. It is difficult to diagnose and manage and can cause the distress to the patient when rupture to cause the bleeding [7]. Most of these pseudo-aneurysms are post-traumatic and post-surgical like tonsillectomy, some of which are related to the infection, inflammation, radiofrequency and chemo-radiotherapy $[1,6]$. There are few cases have been reportedin already diagnosed case of oro-pharyngeal carcinoma presented with oral bleeding [1]. Lingual artery pseudoaneurysms are identified because of active oral bleed, however asymptomatic are discovered incidentally on contrast enhanced CT scan for pre-operative workup and extend of head and neck lesions [2]. Pseudo-aneurysm lack the all three layers of vessel wall caused by arterial wall damage secondary to trauma, iatrogenic injury, surgery, and radiation therap [4].Our patient denied the history of trauma, and surgery but has history of 6 cycles of radiotherapy and chemotherapy, radiotherapy can be the possible cause of pseudo-aneurysm because radiation can induced the vascular wall injury but still unclarified process [4].

Radiological imaging investigations used to diagnose the pseudo-aneurysms are ultrasonography, contrast enhanced CT scan and Magnetic Resonance Imaging (MRI) to see the complete evaluation and extent of lesion [5].

Treatment of choice for pseudo-aneurysm is therapeutic interventional angiography to avoid the surgical ligation of artery and excision of pseudo-aneurysm commonly using embolizing material gelfoam to obtain the complete blockage of pseudo-aneurysmal cavity in order to preserve the patency of main branches of artery and to avoid the more invasive material like coils [5].

In one of literature mentioned that glue mixture with ethiodized oil and n-butyle cyano-acrylate has very effective embolic result and vessels occlusion. It should be injected though the catheter tip which also should be positioned proximal to the injured vessels and to avoid the cannulation of pseudoaneurysm and preventing the perforation of pseudo-aneurysm wall [8]. Surgical ligation is also treatment option for pseudoaneurysm of external carotid artery in patient with uncontrolled bleeding from specific head and neck sites like epistaxis posttonsillectomy hemorrhage and trauma [4]. Endovascular embolization has many advantages over the surgical ligation. It has diagnostic evaluation and therapeutic role. It is also more selective procedure and has less risk of damaging the vagal and accessory nerves [4].

\section{Conclusion}

External carotid artery and its branches rarely develop aneurysm and are mostly post traumatic or post intervention. Lingual artery pseudo-aneurysm although rare but should be kept in mind when treating a patient with oral and lingual tumors, as these can be a cause of bleed in such patients. Hence it is important for a radiologist to be vigilant in reporting such cases and be aware of the imaging findings.

\section{Ethical Review}

This case report was written and images of patient's scan were added after taking consent from patient and patient's identity is not shown here and will be kept confidential.

\section{Conflict of Interest}

The authors report no conflict of interest. The authors alone are responsible for the content and writing of the paper.

\section{Funding}

No funding or grant support.

\section{References}

1. Espallargas I, Marsico S, Zuccarino F, et al. (2020) Pseudoaneurysm of the lingual artery as an unusual radiological finding of oropharyngeal carcinoma. BJR 6(4): p. 20200063.

2. Iwai T, Izumi T, Hayashi Y, et al. (2017) Bilateral idiopathic aneurysms of the lingual artery identified by three-dimensional computed tomography angiography. Oral Radiology 33(3): pp. 227-230.

3. Brindle RS, Fernandez PM, Sattenberg RJ, et al. (2010) Idiopathic Lingual Artery Aneurysm: CT Findings and Endovascular Therapy: A Case Report. Interv Neuroradiol 16(1): pp. 103-106.

4. Murono S, Nakanishi Y, Inoue D, et al. (2011) Pseudoaneurysm of the lingual artery after concurrent intra-arterial chemotherapy with radiotherapy for advanced tongue cancer. Head Neck 33(8): pp. 1230-1232.

5. Salgarelli A, Morana G, Beltramello A, et al. (1997) Pseudoaneurysm of the lingual artery: a case report. J Oral Maxillofac Surg 55(8): pp. 860-864.

6. Maleux O, Hermans R, Vander Poorten V, et al. (2020) Glue embolization of a bleeding lingual artery pseudoaneurysm related to tongue surgery. Acta Chirurgica Belgica 18: pp. 1-3.

7. Radak $Ð$, Davidović L, Vukobratov V, et al. (2007) Carotid artery aneurysms: Serbian multicentric study. Annals Vascul Surg 21(1): pp. 23-29.

8. Cheng L, Kennedy H, Wong K, et al. (2017) Pseudoaneurysm of the lingual artery-a case series. Int J Oral Maxillofac Surg 46: p. 282. 